\title{
Risky Sexual Behavior and Associated Factors Among Sexually-Active Unmarried Young Female Internal Migrants Working in Burayu Town, Ethiopia
}

\author{
Ararso Baru ( $\nabla$ ararsob@gmail.com ) \\ Arbaminch university \\ Ikeola A. Adeoye \\ University of Ibadan College of Medicine \\ Adeyemi O. Adekunle \\ University of Ibadan College of Medicine
}

\section{Research article}

Keywords: Internal migration, young female, sexually-active, risky sexual behavior, Burayu town, Ethiopia

Posted Date: December 9th, 2019

DOI: https://doi.org/10.21203/rs.2.18415/v1

License: (c) (i) This work is licensed under a Creative Commons Attribution 4.0 International License.

Read Full License

Version of Record: A version of this preprint was published at PLOS ONE on October 21st, 2020. See the published version at https://doi.org/10.1371/journal.pone.0240695. 


\section{Abstract}

Background Young female internal migrants are highly vulnerable to risky sexual behaviors (RSB) which may result in serious health problems such as unintended pregnancy, abortion and sexually transmitted infections including HIV. RSB include early sexual debut (before 18 years), having multiple sexual partners, sex without condom or inconsistent use of condom and sex under influence of substance use. This study aimed to assess the magnitude and the factors associated with RSB among sexually-active unmarried young female internal migrants in Burayu Town, Ethiopia.

Methods A cross sectional study design was used for the study. A total of 267 respondents were recruited in to the study using simple random sampling technique. A semi-structured interviewer administered questionnaire was used to obtain information from the study participants. The collected data were cleaned, coded and entered into Epi data version 3.1 and then exported to SPSS Ver.21 for analysis. Multiple logistic regression models were used to indicate the association between dependent and independent variables.

Results About $35 \%$ of the young female internal migrants had sexual debut before age of 18 years; $64.4 \%$ had sex without condom or inconsistently used condom; nearly one quarter of the participants had multiple sexual partners and $29.6 \%$ had sex under influence of substance uses. The magnitude of RSB among the study participants was (79.1\%). Sexting [AOR 3.47(95\%; Cl;1.10-11.94)], frequent indulgence of social media [AOR 10.9(95\%;Cl;2.31-51.89)], feeling of embarrassment to buy condom [AOR 8.28(95\%; $\mathrm{Cl}$; 2.10-32.62)], unfavorable attitude toward using condom for steady and loving relationship [AOR 5.72(95\%; Cl; 1.47-22.24)] were related with RSB while self-efficacy [AOR 0.15(95\%: $\mathrm{Cl} ; 0.04-0.57)$ ] to use condom and perceived risks of getting pregnant [AOR 0.05(95\%; $\mathrm{Cl} ; 0.01-0.23)]$ were found to be protective factors.

Conclusion The study found high levels of RSB among sexually-active unmarried young female internal migrants. This finding suggests an urgent need of intervention to promote safe sex among this group. Special attention and prompt interventions are needed to promote the use of condom. Moreover, intense efforts should be made to improve awareness on the seriousness of exposure to sexting and judicious use of social media among unmarried female internal migrants.

\section{Background}

Ethiopia is one of the developing countries in Sub-Saharan Africa with an estimated 80 percent of population inhabited in the rural area (1). Notwithstanding, the recent urbanization rate in the country is rapidly increasing at about 5.4 percent per year and by 2028 the country's population in urban areas will reach 30 percent (2). Internal migration (mainly rural to urban) is the main reason for the rapid increase (3).

Internal migrations in Ethiopia are due to social, economic, climatic and political factors like elsewhere in sub-Saharan Africa $(4,5)$. The reasons include but not limited to the factors such as drought, war, famine, 
political turmoil, forced migrations, education, searching for a better job opportunity and marriages or escaping from early marriages $(4,6,7)$. Young people are a dominant group among all internal migrant in the country (6-8). However, they are an economically disadvantaged group with little education and limited skills $(6,9)$.

Migration during the formative adolescent and early adult years can affect life-course transitions through several pathways and can lead young people to risky sexual behaviors(10,11). First, migration can alter existing sexual partnerships, and provide mobile individuals an opportunity to acquire new partners. Secondly, migrants are physically separated from their usual social norms and networks so that they may experience social isolation $(12,13)$. Thirdly, they also might feel emotionally distanced from partners at home $(12,14)$. Moreover, migrants have limited knowledge and access to reproductive health services $(15,16)$. So, they are more likely to engage in risky sexual behaviors than non-migrants $(12,14,17,18)$. Risky sexual behavior may result in serious health problems such as unintended pregnancy, abortion and sexually transmitted infections (STIs) including HIV (19).

In Ethiopia, risky sexual behavior was higher among migrants than non-migrants (6,7,20-22). According to the study conducted in Northwest Ethiopia, $80.4 \%$ of young female internal migrants were engaged in risky sexual practices (21). Indeed, there is high prevalence of multiple sexual partners, less utilization of condom and higher proportion of commercial sex engagement among migrants than non-migrants in the country (6).

Most studies conducted on risky sexual behaviors in Ethiopia were mainly focused on key populations such as female sex workers, secondary school students, university students, adolescents, youths and substance users $(6,20,21,23-25)$. Nevertheless, the study that focused on sexual behavior of internal migrants is very limited. As a result, very little is known about the relationship between migration and risky sexual behavior among young female internal migrants in Ethiopia. Therefore, this study examined risky sexual behavior and associated factors among sexually-active unmarried young female internal migrants working in Burayu town, Ethiopia.

\section{Methods}

\section{Study setting and period}

The study was conducted in Burayu town, Ethiopia. The town is located $10 \mathrm{~km}$ to the West of Addis Ababa, the capital city of Ethiopia. The town has six kebele (the smallest administrative unit in Ethiopia). The town's strategic locations (near Addis Ababa city) and availability of infrastructures attracted domestic and foreign investors to the town. As a result, a large number of young people mostly from rural and semi urban areas move to the town to find better work opportunity. This study included three of the kebele located in Burayu town namely Lakku katta, Burayyu katta and Gafarsa nonno. In addition, the study was done from April to June 2019 among participants recruited from factories, restaurants, hotels, cafeterias, bars and beauty salons located in the selected kebele. 


\section{Study design, participants and sampling procedures}

A cross-sectional study design was conducted to assess the magnitude and factors associated with risky sexual behaviors among sexually active unmarried young female internal migrants.

Sample size (n) was determined based on a single population proportion formula with the following assumptions. The prevalence of risky sexual behavior among young female internal migrants was $80.4 \%$, which was taken from a study conducted in Tiss Abay town, Ethiopia (21). The level of confidence (a) was set at $0.05(Z(1-a)=1.96)$ and the margin of error was taken as 0.05 . Accordingly, the calculated sample size with $10 \%$ consideration for non-response rate was 267 .

Eligibility criteria included being female, being in the age group of 15-24 years, had experience of penetrative sexual intercourse over the last six months, unmarried, internal migrants, employed in one of the requirement settings and having consented to participate in the study.

Prior to recruitment, informational leaflets about the survey were distributed to the staff in each recruitment site. Of the 783 individuals who were screened for eligibility, 267 participants were recruited to the study based on the calculated sample size. All the eligible women gave informed consent to participate in the study. To select the study subjects, sampling frames were developed from leaflets of individuals who were eligible for the study. Therefore, study subjects were selected by simple random sampling technique.

\section{Data collection techniques and instrument}

An interviewer-administered structured questionnaire was used to collect information from each participant. The English version of the questionnaire was adopted from a WHO standard questionnaire on sexual and reproductive behaviours of young people with modification to fit the objectives of the study. The questionnaire had both open and close ended questions to address all questions pertinent to the study. The key factors that were associated with young female internal migrant's risky sexual behaviors were organized and classified as socio-economic and demographic characteristics, behavioral and motivational characteristics, and cognitive and psychological characteristics.

\section{Measurement}

Risky Sexual behavior measurement: for the purposes of this study, RSB are considered as initiating sexual debut before the age of 18 , not using or inconsistent condom use, sex under the influence of substances and having multiple sexual partners. Other studies also recognized these as measure of risky sexual behavior $(20,26)$. The participants were asked all of the questions created to measure risky sexual behavior. These variables are defined as: (a) Subjects had more than one sex partners at a time over the last six months in a period after migration, (b) The respondent initiated the first sexual intercourse before age of 18 years in the period after migration or currently less than 18 years old and experienced penetrative sexual intercourse over the last six months in a period after migration but initiated sexual intercourse before migration, (c) Subjects had sexual intercourse without condom or inconsistent use of 
condom during the last 6 months preceding the date of the survey and in the period after migration, (d) Subjects had sexual intercourse under influence of substance use (like alcohol, khat and shisha) during the last 6 months preceding the date of the survey and in the period after migration.

Perceived risks of contracting HIV/STIs were measured by the question that asked "Were you ever concerned that you might contract AIDS or another sexually transmitted disease from your sexual partner?" This dichotomous measure was coded 1= yes, if they had ever used a condom, 0 if otherwise.

\section{Data quality assurance}

The qualities of data were assured through careful design, translation and retranslation of study tool language from English version to local languages (Amharic and Afan Oromo) and vice versa. The questionnaire was pretested before data collections and possible corrections were made. Besides, two days training for the interviewers and supervisors were conducted. The confidential face-to-face survey interviews were conducted by trained female data collectors of similar age to the participants due to sensitive nature of the queries. In addition, the pilot test was done but the results were not included to the actual study. Based on the feedback from the pilot study, immediate corrective measures were taken. Furthermore, continuous and close supervision of the data collecting procedures, proper categorization, and coding of the data were done. The Principal Investigators and the supervisors checked completeness and consistency of data on a daily basis.

\section{Data entry, processing and analysis plan}

Data were checked for completeness and inconsistencies. Then, they were cleaned, coded and entered to EPI data for validation. Lastly, it was exported to Statistical Package for Social Science (SPSS) version 21 for analysis.

Descriptive statistics were used to summarize the data while table and diagrams were used to present information. Binary logistic regression was used to observe associations between dependent and independent variables. Purposive selections of variable with a $p$-value of $<0.25$ on bivariate analysis were considered for binary logistic regression to control the effect of other confounders. Then, a significant level was set at $\mathrm{p}<0.05$.

\section{Ethical consideration}

Ethical clearance was obtained from University of Ibadan /University College Hospital (UI/UCH) Ethical Review Board. Similarly, clearance was obtained from the Oromia Regional Health Bureau (ORHB). The ORHB directed the Burayu town's health Bureau and respective institutions to allow the study to be conducted.

The purpose of the study was explained and verbal consent was obtained from each study participant prior to the interviews. The respondents were informed that they had the right to be involved or refuse to participate in the study. In addition, the respondent had the right to withdraw from the study at any time 
during the interview. The participants were assured that the data would be handled exclusively by the investigators and no one would be able to recognize them in the report. Confidentiality of the information obtained from each participant was maintained.

\section{- Operational Definition}

Young female: in this study, referred to women aged between 15-24 years of age.

Risky sexual behavior (RSB) is defined as any sexual activity that increases the risk of contracting sexually transmitted infections and unintended pregnancies. It includes having sex with multiple sexual partners, not using or inconsistent condom use, sex under the influence of substances and initiation of sex before the age of 18 years. An individual is considered as engaging in risky sexual practice if she experienced at least one or more of the above behaviors $(20,26)$.

Migrants: are those whose current places of residence are outside their places of childhood residence prior to the survey

Internal migration: refers to people within a country moving to another location within its borders.

Consistent condom use is the behavior that youth uses a condom at every sexual contact or intercourse on a continuous basis.

Adequate knowledge about male condom: The respondents who were agreed on the following questions were categorized as they had adequate knowledge about condoms. (a) having heard about the male condom (b) had ever seen a male condom in demonstration (c) had knowledge that they prevent HIV/STD (d) had knowledge that they prevent unplanned pregnancy and being able to mention at least three forms of care needed for the correct use of the male condom.

Inadequate knowledge about male condom: never having heard about the male condom or having heard, but never seen a male condom in demonstration or not know as it serve to prevent STD/HIV; or when the respondent could not mention at least three forms of care needed for the correct use of male condom.

\section{Results}

\section{Socio-demographic characteristics of the participants}

The majority 153 (57.3\%) of the participants were in the 15-19 years' age (with a mean= of 18.85 years), $(\mathrm{SD}=2.337)$. With regard to religious affiliation, majority $(123\{46.1 \%\})$ of the participants were protestants and 98(36.7\%) were Ethiopian orthodox religion followers. In addition, nearly half $(124\{46.4 \%\})$ of the study participants attended religious service more than once per week. 
Table 1: Percentage distribution of socio-demographic characteristics of sexually active unmarried young female internal migrants in Burayu town, Ethiopia

\begin{tabular}{lll}
\hline Variables & Frequency (N=267) & Percentage (\%) \\
\hline Age of respondent & \\
(Mean=18.85 years, S.D=2.337, Variance=5.464) & & \\
15-19 years & 153 & 57.3 \\
20-24 years & 114 & 42.7 \\
Religious affiliation & 123 & 46.1 \\
Protestant & 98 & 36.7 \\
Ethiopian Orthodox & 29 & 10.9 \\
Muslim & 17 & 6.4 \\
Others & & \\
Frequency of attending religious service & 124 & 46.4 \\
More than once a week & 101 & 37.8 \\
Never attend & 42 & 15.7 \\
Educational Status & & \\
Primary & 46 & 17.2 \\
Secondary & 116 & 43.4 \\
Tertiary & 105 & 39.3 \\
Currently studying & & 36.3 \\
No & 97 & 63.7 \\
Place of residence before migration & 170 & \\
Urban & & 47.2 \\
Rural & 126 & 52.8 \\
Length of time stayed in Burayu & 141 & 51.7 \\
<2 years & & 27.7 \\
>5 years & 138 & 20.6 \\
Live with at least one member of their family & 74 & \\
Yes & 55 & 27.7 \\
No & & 72.3 \\
Monthly income in Ethiopian Birr* & 74 & 27.7 \\
1000-2000 & 193 & 57.3 \\
>2000 & 74.0 \\
\hline
\end{tabular}

Behavioral characteristics of study participants

This study revealed that more than one-fourth $(73\{27.3 \%\})$ of the study participants went to the clubs over the last six months while one-fifth $(53\{19.9 \%\})$ of them went to the cinema or movie houses. Ninety-two (34.5\%) study participants watched pornography at least once over the last six months. Nearly three-fourth $(195\{73.0 \%\})$ of the study participants used social media and the majority $(107\{54.9 \%\})$ of these used it many times daily. In addition, 
94(48.4\%) respondents who were active on the social media indulged in sexting with men over the last six months.

With regard to substance use, more than half (136 $50.9 \%\})$ of the participants used alcohol, 47(17.6\%) chewed khat while 63\{23.6\%) respondents smoked cigarettes or weeds.

Table 2: Percentage distribution of behavioral characteristics of sexually active unmarried young female internal migrants in Burayu town, Ethiopia

\begin{tabular}{lll}
\hline Variables & Frequency (N=267) & Percentage (\%) \\
\hline Went to clubs or parties over the last 6 months & 73 & 27.3 \\
Yes & 194 & 72.7 \\
No & & \\
Went to cinema house over the last 6 months & 53 & 19.9 \\
Yes & 214 & 80.1 \\
No & & \\
Currently use alcohol & 136 & 50.9 \\
Yes & 131 & 49.1 \\
No & & \\
Currently chew Khat & 47 & 17.6 \\
Yes & 220 & 82.4 \\
No & & \\
Currently smoked cigarettes/weeds & 63 & 23.6 \\
Yes & 204 & 76.4 \\
No & & 34.5 \\
Watched pornography & 92 & 65.5 \\
Yes & 175 & 73.0 \\
No & & 27.0 \\
Use social media & 195 & 54.9 \\
Yes & 72 & 22.1 \\
No & & 23.1 \\
Frequency of use of social media* & 107 & 48.2 \\
Many times a day & 43 & 51.8 \\
Several times a week & 45 & \\
Once a while & & \\
Yes & 94 & \\
No & 101 & \\
\hline
\end{tabular}

‘*’ Indicates $N=195$

Table 3: Percentage distribution of sexuality and reproductive health characteristics of sexually active unmarried young female internal migrants in Burayu town, Ethiopia 


\begin{tabular}{|c|c|c|}
\hline Variables & $\begin{array}{l}\text { Frequency } \\
(\mathrm{N}=267)\end{array}$ & $\begin{array}{l}\text { Percentage } \\
\text { (\%) }\end{array}$ \\
\hline \multicolumn{3}{|l|}{ Marital status of the most recent sexual partner } \\
\hline Single & 199 & 74.5 \\
\hline Married & 28 & 10.5 \\
\hline Divorced & 25 & 9.4 \\
\hline Separated & 15 & 5.6 \\
\hline \multicolumn{3}{|l|}{ Self-description of the relationship with partner } \\
\hline Casual & 59 & 22.1 \\
\hline $\begin{array}{l}\text { A serious relationship but with no intention of } \\
\text { marriage }\end{array}$ & 67 & 25.1 \\
\hline Important and might lead to marriage & 86 & 32.2 \\
\hline Engaged to be married & 55 & 20.6 \\
\hline \multicolumn{3}{|l|}{ Had sex without their willingness } \\
\hline Yes & 69 & 25.8 \\
\hline No & 198 & 74.2 \\
\hline \multicolumn{3}{|l|}{ Discussed about $S R H$ with $\geq 1$ family members } \\
\hline Yes & 52 & 19.5 \\
\hline No & 215 & 80.5 \\
\hline \multicolumn{3}{|l|}{ Received SRH information at current destination } \\
\hline Yes & 121 & 45.3 \\
\hline No & 146 & 54.7 \\
\hline \multicolumn{3}{|l|}{ Ever received SRH information at school } \\
\hline Yes & 181 & 67.8 \\
\hline No & 86 & 32.2 \\
\hline \multicolumn{3}{|l|}{ Discussed about FP and STIs with their partner } \\
\hline Yes & 166 & 62.2 \\
\hline No & 101 & 37.8 \\
\hline \multicolumn{3}{|l|}{ Experienced pressure for sexual intercourse } \\
\hline Yes & 135 & 50.6 \\
\hline No & 132 & 49.4 \\
\hline \multicolumn{3}{|l|}{ Had planned first sex at current destination } \\
\hline Yes & 68 & 25.5 \\
\hline No & 199 & 74.5 \\
\hline \multicolumn{3}{|l|}{ Had intergenerational sexual intercourse } \\
\hline Yes & 82 & 30.7 \\
\hline No & 185 & 69.3 \\
\hline \multicolumn{3}{|l|}{ Gave sex after food invitation or other gifts } \\
\hline Yes & 79 & 29.6 \\
\hline No & 188 & 70.4 \\
\hline \multicolumn{3}{|l|}{ Gave sex in exchange for money } \\
\hline Yes & 47 & 17.6 \\
\hline No & 220 & 82.4 \\
\hline
\end{tabular}

Table 4: Risk perception, knowledge and attitude toward condom use among sexually-active unmarried young female internal migrants in Burayu town, Ethiopia 


\begin{tabular}{lll}
\hline Variables & Frequency(N=267) & Percentage (\%) \\
\hline Knowledge about condom & 101 & 37.8 \\
Adequate & 166 & 62.2 \\
Inadequate & 161 & 60.3 \\
I feel embarrassed to buy condom & 106 & 39.7 \\
Agree & & \\
Disagree & 130 & 48.7 \\
Condoms are suitable for steady & 137 & 51.3 \\
and loving relationships & & 48.3 \\
Agree & 129 & 51.7 \\
Disagree & 138 & \\
Condoms reduce sexual pleasure & & 83.1 \\
Agree & 222 & 16.9 \\
Disagree & 45 & 70.4 \\
Condoms are suitable for casual relationships & & 29.6 \\
Agree & 188 & 49.1 \\
Disagree & 79 & 50.9 \\
Condoms should be used in premarital sex & & \\
Agree & 131 & 67.4 \\
Disagree & 136 & 32.6 \\
Using condom is distrusting your partner & & \\
Agree & 180 & 32.2 \\
Disagree & 87 & 67.8 \\
A girl can suggest the use of condom & & 58.4 \\
Agree & 181 & 41.6 \\
Disagree & & 45.3 \\
I have self-efficacy toward condom use & 156 & 54.7 \\
Agree & 111 & \\
Disagree & 121 & \\
Perceived risks of contracting HIV/STIs & 146 & \\
Yes & & \\
No & & \\
Yerceived risks of getting pregnant & & \\
No & & \\
\hline
\end{tabular}

[Figure 1]

Table 5: Factors associated with risky sexual behavior among sexually-active unmarried young female internal migrants in Burayu town, Ethiopia 


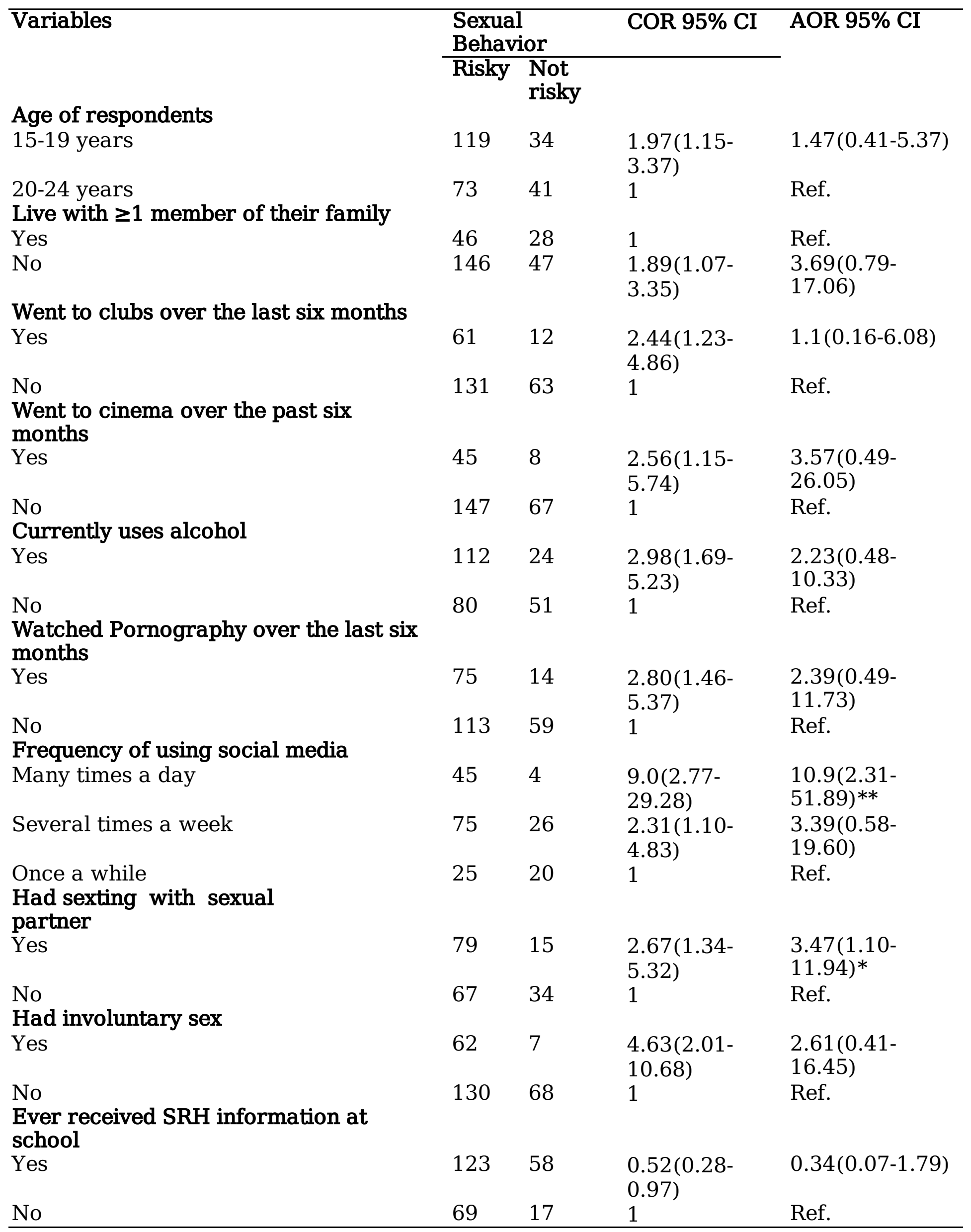


Table 5: Factors associated with risky sexual behavior among sexually-active unmarried young female internal migrants in Burayu town, Ethiopia (Continued)

\section{Variables}

Had planned the first sex after migration

Yes

No

Gave sex after food invitation or other gifts

Yes

No

Gave sex in exchange for money

Yes

No

Able to refuse sex without condom

Yes

No

Perceived risks of contracting HIV/STIs Yes

No

Perceived risks of getting pregnant Yes

No

Knowledge about condom

Adequate

nadequate

[ feel embarrassed to buy condom

Agree

Jisagree

[ use condom in steady and loving relationships

Agree

Jisagree

\begin{tabular}{ll} 
Sexual & \\
Behavior \\
\hline Risky & $\begin{array}{l}\text { Not } \\
\text { risky }\end{array}$
\end{tabular}

COR 95\% CI AOR 95\% CI

$40 \quad 28$

$152 \quad 47$

1

$2.26(1.26-$

4.06)

Ref.

3.56(0.75-

16.96)

$60 \quad 9$

$3.36(1.57-$

7.19)

$131 \quad 66$

1

$15.62(0.91-$

267.96)

Ref.

$42 \quad 5$

$150 \quad 70$

3.92(1.49-

10.34)

9.64(0.53-

175.02)

Ref.
$0.10(0.05-$

$0.20)$

1

$0.34(0.18-$

0.61 )

$93 \quad 18$

1

$0.21(0.12-$

0.37 )

$125 \quad 21$

1

$0.41(0.24-$

0.70 )

$131 \quad 35$

$$
1
$$

$0.15(0.04-$

$0.57)^{* *}$

Ref.

$\begin{array}{llll}61 & 40 & 0.41(0.24- & 0.48(0.13-1.77) \\ & & 0.70) & \text { Ref. }\end{array}$

$\begin{array}{llll}136 & 25 & 4.86(2.74- & 8.28(2.10- \\ & & 8.61) & 32.62)^{* *} \\ 56 & 50 & 1 & \text { Ref. }\end{array}$

$75 \quad 55$

1 Ref.

$117 \quad 20$

4.29(2.38-

7.73) 


\section{${ }^{*} \mathrm{p}<0.05 * * \mathrm{p}<0.01 * * * \mathrm{p}<0.001$}

\section{Discussion}

In this study, $34.5 \%$ study participants had sexual debut before ages of 18 years. This finding was much higher than the report of study conducted in China (17\%) (17). However, it was lower (49.8\%) than that of the study from Nigeria (27). This difference might be explained by the educational, economic, and healthcare disparities between countries. For instance, Chinese inhabitants might enjoy better socioeconomic prosperity and better healthcare facilities that provide SRH services than Ethiopia. In addition, the study from Nigeria was conducted among reproductive age group women while the present study only included young female. So, due to the age difference, the respondents from the study conducted in Nigeria might be more susceptible to recall bias than the present study participants. Thus, the study in Nigeria might overestimate the magnitude of RSB and could be a reason for the difference.

Nearly one-fourth $(23.97 \%)$ of the study participants had multiple sexual partners during the last six months. Similar finding have been reported among female internal migrant workers in China (28).

This study found that $64.4 \%$ of the respondents had sex without condom or inconsistently used condom in their most recent sexual intercourse during the last six months. Likewise, the study conducted among unmarried female migrants from Shanghai reported nearly similar finding, (66.8\%) (29). On the other hand, another study from China reported higher (84\%) prevalence of sex without condom or inconsistent use of condom among female internal migrants workers (28). The discrepancy might be due to the fact that the study in China measured condom use over the last three most recent sexual intercourses while this study measured only the most recent sexual intercourse. This might underestimate the prevalence of sex without condom or inconsistent use of condom in the present study.

The magnitude of risky sexual behavior among study participants in this study was $71.9 \%$. This finding was lower than the results reported from Tiss Abay town of Amhara regional state of Ethiopia (80.4\%) (21). The disparity could be due to the fact that the present study was conducted among all types of internal migrants while the study from Tiss Abay town was done mainly among rural to urban migrants. In addition, Tiss Abay town is semi-urban and the study showed that the migrants in small urban areas acquire reproductive health knowledge sooner than migrants in the metropolitan area (30).

More than one-third (34.5\%) of the study participants watched pornography at least once over the last six months. This finding was higher than that of the study conducted in Jimma town of Ethiopia among preparatory students (25). This study was done among internal migrants while the study from Jimma town was among preparatory students who were combination of both migrants and non-migrants. This could be the reason for the difference because of the fact that an internal migrant has less control from family so that they could engage themselves in activities that deviate from their culture (31).

Nearly three-fourth $(73.0 \%)$ of the study participants used social media and the majority $(54.9 \%)$ of these used it many times daily. In addition, about (48.4\%) of the respondents who were active on the social 
media indulged in sexting with men over the last six months. This finding was higher than the result of the studies conducted in the United States $(32,33)$.

This study found that, one-fourth $(25.8 \%)$ of the study participants were raped by their sexual partners or strangers over the last six months preceding the data collections period. The studies conducted in Northwest Ethiopia among street females (34) and that conducted in Southern Ethiopia among university students (35) found similar results even though they reported life time and one-year prevalence of rape, respectively.

Regarding the discussion and communication with family about SRH, only one-fifth (19.5\%) of the study participants ever discussed about SRH with at least one of their family members. Even though the study population was different, an earlier study conducted among internal migrant children in Ethiopia reported that $21 \%$ of the migrant parents talked to them about HIV and only $11 \%$ reported discussions on sex (8).

The majority $(156\{58.4 \%\})$ of the respondents expressed the perceived risks of contracting HIV. However, this finding was lower than the result reported from China, $(71.0 \%)(36)$. The difference might be that the present study used only young age groups while the study from China was conducted among all age groups. Older people might have higher risk perception than younger age group.

Even though it was only in bivariate analysis, age of the study participants has statistically significant association with sexual behavior, [COR 1.97(95\%; Cl; 1.15-3.37)]. After adjustment for potential covariates, age of the study participants has no statistically significant association with sexual behavior of the respondents' [AOR 1.47(95\%; Cl; 0.41-5.37)]. Consistent with this study finding, younger age was reported as predictors of internal migrants' risky sexual behavior on previous studies $(36,37)$.

The unadjusted analysis showed that alcohol use was associated with risk sexual behavior of young female internal migrants, [COR 2.98(95\%; Cl; 1.69-5.23)]. The reason might be due to the nature of alcohol in decreasing attention to safe sex practices, altering rational decision-making and increasing risk-taking behaviors $(38,39)$.

Recent technology is facilitating the tendency to have multiple sexual partners and practical sexual behavior as reported in previous studies $(32,33)$. In this study, the respondents who shared sexually explicit texts, images or/and videos with their sexual partners over social media were about 3.5 times more likely to experience risky sexual behavior than those never sexted, [AOR 3.47(95\%; Cl;1.10-11.94)]. Consistent with this study finding, sexting of any kind was associated with higher rates of engaging in a variety of sexual behaviors but the impact of image-sexting are more prominent than pure texting (40). In contrary, study from United States reported that sexting was not associated with risky sexual behaviors (32). Further studies are recommended for a better understanding of the association between sexting and risky sexual behavior.

In bivariate analysis, the respondents who were forced to have sex over the last six months preceding the field data collection were 4.65 times more likely to have risky sexual behavior than their counterparts, 
[COR 4.63(95\%; Cl; 2.01-10.68)]. It is not surprising that rape victims were vulnerable to risky sexual behavior in previous studies $(34,35)$.

Young women who had received sexuality education through schools, parents or other family members were less likely to engage in risky sexual behaviors in previous studies $(41,42)$. Consistent with the former studies, unadjusted analysis showed that school-based sexuality and reproductive health information predict risky sexual behavior of the study participants in this study, [COR 0.52(95\%; Cl; 0.28-0.97)]; However, this association was not more established on multivariate analysis, [AOR 0.34(95\%; Cl; 0.071.79)].

Statistically significant association was established between respondents who exchanged sex for money despite the fact that there was no significant association on the adjusted analysis. The unadjusted analysis implies that the study participants who gave sex in exchange for money were nearly four times more likely to have risky sexual behavior than their counterparts, [COR 3.92(95\%; Cl; 1.49-10.34)]. Similar to this study, transactional sex was associated with risky sexual behavior according to the study conducted in Northwest Ethiopia (21).

Previous studies finding reported that the women who reported hunger were more likely to engage in transactional sex which was significantly exposed them to unprotected sexual intercourse $(18,43)$. The unadjusted finding of this study also found statistically significant association, [COR 3.36(95\%; Cl; 1.577.19)]. A possible explanation for this result is that migrants are economically disadvantaged, so that they might have been participated in risky behavior to support their daily life.

The study participants who reported feeling of embarrassment to buy condom were about eight times more likely to have risky sexual behavior than their counterparts on adjusted analysis, [AOR 8.28(95\%; $\mathrm{Cl}$; 2.10-32.62)]. In agreement with this finding, previous studies identified embarrassment to buy condom as a key risk factor in young people's sexual behaviour $(41,44)$. Moreover, the respondents who had negative attitude about the use of condom for steady and loving relationships were about six times more likely to have risky sexual behavior than those who had positive attitude about the importance of condom for the same purpose on multivariate analysis, [AOR 5.72(95\%; Cl; 1.47-22.24)]. Young people believe that condoms do not play a role in a relationship based on love and they are less likely to perceive themselves at risk of contracting HIV/AIDS or unwanted pregnancy according to the report from a previous study (45).

The women who reported ability to refuse sex without condoms were $85 \%$ less likely to have risky sexual behavior than their counterparts in this study, [AOR 0.15(95\% Cl; 0.04-0.57)].In agreement with this study, finding from Cameroon showed that self-efficacy was protective factor of sexual behavior (46).

The perceived risks of getting pregnant has statistically significant association with risky sexual behavior both on bivariate and multivariate analysis, [COR 0.21(95\%; Cl; 0.12-0.37)] and [AOR 0.05(95\%; Cl; 0.01$0.23)]$, respectively. This means that the women who reported perceived risks of getting pregnant were 
$95 \%$ less likely to have risky sexual behavior than their counterparts after adjustment for potential confounders.

\section{Limitation of the study}

This study results should be interpreted while considering several limitations. First, we cannot draw causal conclusions owing to the cross-sectional design of the study. Secondly, given that the sample population was limited to one city, the investigator could not assert that it is representative of all sexuallyactive unmarried female migrant workers in Ethiopia. Thirdly, this study was limited in its reliance on selfreported data because it is a sensitive topic; however, we tried our best to obtain unbiased responses. Despite these limitations, this study identified a range of major reproductive health issues related to young female internal migrants that affect their sexual behavior which was probably underexplored in Ethiopia by previous studies.

\section{Conclusion}

A considerable proportion of sexually active unmarried young female internal migrants practice risky sexual behavior which endangers their future life. More than one-third of the unmarried young female migrants had sexual debut before age of 18 years; nearly one-fourth of the study participants had multiple sexual partners during the last six months; almost two-thirds of the respondents had sex without condom or inconsistently used condom on their most recent sexual intercourse and about three out of ten respondents had sex under the influence of alcohol.

Some variables were found to have been associated with risky sexual behaviour in this study. These included sexting, frequent indulgence of social media, feeling of embarrassment to buy condom, unfavorable attitude towards using condom for steady and loving relationship. Even though the association was not established after adjustment, age of respondent, family composition, frequency at clubs or parties, cinema house, watching pornography, alcohol use, rape, planned first sex after migration and transactional sex were also associated with risky sexual behavior.

Perceived self-efficacy to use condom and perceived risks of getting pregnancy were found to be protective of risky sexual behavior among unmarried young female internal migrants. In addition, adequate knowledge of condom, school-based SRH education, parental child communication on SRH and perceived risks of contracting HIV/STIs were also protective of risky sexual behavior on unadjusted analysis.

This finding suggests an urgent need of intervention to promote safe sex among this group. Special attention and prompt interventions are needed to promote the use of condom. Such interventions should include targeting the prevailing misconceptions, unfavorable attitudes and other dynamics related to not using condom or inconsistent condom use which was prominent in this study. Strategies to channel young female internal migrants into productive and safe livelihoods should be emphasized to minimize 
rape, transactional sex and sex work. The study also suggests that more intense efforts should be made to improve awareness about the seriousness of exposure to sexting. In addition, judicious use of social media among sexually-active unmarried young female internal migrants is needed.

\section{Abbreviations}

AB: Ararso Baru; AIDS: Acquired Immuno-deficiency Syndrome; AOA: Adeyemi O. Adekunle; AOR: Adjusted odds ratio; COR: Crude odds ratio; FGD: Focus Group Discussion; HIV: Human Immuno-deficiency Virus; IAA: Ikeola A. Adeoye; RSB: Risky Sexual Behaviour; SRH: Sexual and Reproductive Health; SPSS: Statistical Package for Social Sciences; STIs: Sexually Transmitted Infections; USAID: United States Agency for International Development; UNFPA: United Nations Fund for Population Activities; PAULESI

\section{Declarations}

\section{Ethics approval and consent to participate}

Ethical clearance was obtained from University of Ibadan /University College Hospital (UI/UCH) ethical review board. Similarly, clearance was obtained from the Oromia Regional Health Bureau (ORHB) through PAULESI. The ORHB directed the Burayu town's health Bureau and respective institutions to allow the study to be conducted.

The purpose of the study was explained and verbal consent was obtained from each study participant prior to the interviews. The respondents were informed that they had the right to be involved or refuse to participate in the study. In addition, the respondent had the right to withdraw from the study at any time during the interview. The participants were assured that the data will be handled exclusively by the investigators and no one would be able to recognize them in the report. Confidentiality of the information obtained from each participant was maintained.

\section{Consent for publication}

Not applicable.

\section{Availability of data and materials}

The datasets used and/or analyzed during the current study are available from the corresponding author on reasonable request.

\section{Competing Interest}

The authors declare that they have no competing interests

\section{Funding}


Authors would like to declare that funding was not received for this study. However, logistic support that covered expense for duplication of study tools, data collections and transportations which were covered by Pan African University Life and Earth Science Institute including Health and Agriculture (PAULESI).

\section{Author's contribution}

Ararso Baru made substantial contributions to conception, design, acquisition of data, analysis, interpretation of data, drafting of the manuscript and the critical review of the draft manuscripts. AOA and IAA were assisted with the design, analysis, and interpretations of the data and the critical review of the manuscript drafts. All authors read and approved the final draft of the manuscript.

\section{Acknowledgements}

Our deepest gratitude goes to Pan African University and the management of Oromia regional Health Bureau for facilitating this study. Finally, our special respect goes to all respondents and data collectors in this study.

\section{References}

1. United Nations, Department of Economic and Social Affairs, Population Division. World Urbanization Prospects: The 2014 Revision, Highlights (ST/ESA/SER.A/352) [Internet]. Demographic Research. 2014. Available from: http://esa.un.org/unpd/wup/Highlights/WUP2014-Highlights.pdf

2. The World Bank. Ethiopia Economic Update II: Laying the Foundation for Achieving Middle Income Status. Washington, DC; 2013.

3. Blunch N, Laderchi CR, Blunch N. The Winner Takes It All: Internal Migration, Education and Wages in Ethiopia. IZA. 2015;(8926).

4. Regassa N. Gender Differentials in Migration Impacts in Southern Ethiopia. Anthropologist. 2009;12(2):129-37.

5. Mberu BU. Who Moves And Who Stays? Rural Out-Migration In Nigeria Author ( $s$ ): Springer J Popul Res [Internet]. 2005;22(2):141-61. Available from: http://www.jstor.org/stable/41110833

6. Tamiru, M., Hailemariam, D., Mitike, G.,Haidar, J. HIV-Related Sexual Behaviors among Migrants and Non migrants in Rural Ethiopia: Role of Rural to Urban Migration in HIV Transmission. Int J Biomed Sci HIV-Related. 2011;7(4):295-303.

7. Erulkar, A.S., Mekbib, T., Semie, N., \& Gulema T. Migration and Vulnerability among Adolescents in Slum Areas of Addis Ababa, Ethiopia. J Youth Stud. 2006;9(3):361-74.

8. Erulkar A., Medhin G. NL. Out-of-School Girls in Ethiopia: Examining Migration , Livelihoods , And HIV: Addis Ababa. Popul Counc. 2017;1-38. 
9. The World Bank. The Ethiopian Urban Migration Study 2008:The Characteristics, Motives And Outcomes Of Migrants To Addis Ababa. 2010.

10. Luke Nancy, Hongwei Xu, Blessing U. Mberu REG. Migration Experience and Premarital Sexual Initiation in Urban Kenya: An Event History Analysis. Stud Fam Plann. 2012;43(2):115-26.

11. Blessing Uchenna Mberu, MJW. Internal Migration and Sexual Initiation among Never Married Youths in Nigeria. Soc Sci Med. 2011;72(8):1284-93.

12. Hirsch JS, Muñoz-Laboy M, Nyhus CM, Yount KM BJ. "Because He Misses His Normal Life Back Home": Masculinity and Sexual Behavior Among Mexican Migrants in Atlanta, Georgia. Perspect Sex Reprod Heal. 2009;41(1):23.

13. Apostolopoulos Y, Sonmez S, Kronenfeld J, Castillo E, McLendon L, Smith D. STI/HIV Risks for Mexican Migrant Laborers: Exploratory Ethnographies. . J Immigr Minor Heal 2006. 2006;8(3):291-2.

14. Shedlin MG, Decena CU, Oliver-Velez D. Initial acculturation and HIV risk among new Hispanic immigrants. J Natl Med Assoc. 2005;

15. Islam MM, Gagnon AJ. Use of reproductive health care services among urban migrant women in Bangladesh. BMC Womens Health [Internet]. BMC Women's Health; 2016;16(1):1-7. Available from: http://dx.doi.org/10.1186/s12905-016-0296-4

16. Cai Jin, Yong Wang, Ying Zheng, Zhijie Wang, Jin Yao WM. Predictors of Reducing Sexual and Reproductive Risk Behaviors Based on the Information-Motivation- Behavioral Skills ( IMB ) Model among Unmarried Rural- To-Urban Female Migrants in Shanghai , China. 2013;8(4):1-7.

17. Huang Hongbo, Wen Operario, Don Dong, Yanyan Zaller, Nickolas Song, Dandan He, Huan Tao, Haidong Xia JZ. HIV-Related Risk Among Female Migrants Working in Entertainment Venues in China. Prev Sci. 2015;15(3):329-39.

18. Carol S.Camlin , Zachary A. Kwena, Shari L. Dworkin, Craig R. Cohen EAB. "She mixes her business": HIV transmission and acquisition risks among female migrants in western Kenya. Soc Sci Med. 2015;102:146-56.

19. Wang, Y., Yao, W., Shang, M., Cai, Y., Shi, R., Ma, J., Wang, J., Song, H. Sexual and reproductive health among unmarried rural-urban female migrants in Shanghai China: a comparative analysis. Int $\mathrm{J}$ Environ Res Public Health. 2013;10(8):3578-89.

20. Desale AY, Argaw MD, Yalew AW. Prevalence and Associated Factors of Risky Sexual Behaviours Among in-School Youth in Lalibela Town, North Wollo Zone, Amhara Regional Sate, Ethiopia: A Cross-Sectional Study Design. Sci J Public Heal Vol. 2016;4(1):57-64.

21. Tadesse G, Yakob B. Risky sexual behaviors among female youth in Tiss Abay, a semi-urban area of the Amhara Region, Ethiopia. PLoS One. 2015;10(3):1-16.

22. Sori AT. Poverty, Sexual Experience and HIV Vulnerability Risks: Evidence from Addis Ababa, Ethiopia. J Biosoc Sci,. 2012;44:677-701.

23. Abate E, Andargie T, Minale T, Mulat S, Ayele A, Desalegne A. Chewing khat and risky sexual behavior among residents of Bahir Dar City administration, Northwest Ethiopia. Ann Gen Psychiatry [Internet]. BioMed Central; 2018;17(26):1-9. Available from: https://doi.org/10.1186/s12991-018-0194-2 
24. Gebresllasie F, Tsadik M, Berhane E. Potential predictors of risk sexual behavior among private college students in Mekelle City, North Ethiopia. Pan Afr Med J. 2017;28:1-11.

25. Netsanet F , Abebe M. Risky Sexual Behaviors And Associated Factors Among Male And Female Students In Jimma Zone Preparatory Schools, South West Ethiopia: Comparative Study. Ethiop J Heal Dev. 2014;24(1):59-68.

26. Eaton DK, Kann L, Kinchen S, Shanklin S, Ross J, Hawkins J, et al. Youth risk behavior surveillanceUnited States, 2009. Morbidity and mortality weekly report Surveillance summaries. 2010;59(5):1142.

27. Yaya S, Bishwajit G. Age at First Sexual Intercourse and Multiple Sexual Partnerships Among Women in Nigeria: A Cross-Sectional Analysis The Survey and Sampling Design. Front Med. 2018;5(171):18.

28. Yang, H., Li, X., Stanton, B., Fang, X., Lin, D., Mao, R., Liu, H., Chen, X. Workplace and HIV-related sexual behaviours and perceptions among female migrant workers. AIDS Care. 2007;17(7):819-33.

29. Luo M, Zhu L, Dong Y, Wang Z, Shen Q, Mo D, et al. Sexual compulsivity and its relationship with condomless sex among unmarried female migrant workers in Shanghai , China: a cross-sectional study. BMC Womens Health. 2018;18(181):1-7.

30. David P. Lindstrom and Coralia Herrera Hernández. Internal Migration and Contraceptive Knowledge And Use in Guatemala. Int Fam Plan Perspect. 2006;32(3):146-53.

31. Yang X. Rural - urban migration and mental and sexual health: a case study in Southwestern China. Heal Psychol Behav Med [Internet]. Taylor \& Francis; 2014;2(1):1-15. Available from: http://dx.doi.org/10.1080/21642850.2013.839384

32. Temple AJR, Choi H. Longitudinal Association Between Teen Sexting and Sexual Behavior. Pediatrics. 2019;134(5):e1287-92.

33. Benotsch EG, Snipes DJ, Martin AM, Bull SS. Sexting, Substance Use, and Sexual Risk Behavior in Young Adults. J Adolesc Heal [Internet]. Elsevier; 2013 Mar 1 [cited 2019 Aug 18];52(3):307-13. Available from: https://www.sciencedirect.com/science/article/abs/pii/S1054139X12002327

34. Misganaw AC, Worku YA. Assessment of sexual violence among street females in Bahir-Dar town , North West Ethiopia: a mixed method study. BMC Public Health. 2013;13(825):1-8.

35. Adinew YM, Hagos MA. Sexual violence against female university students in Ethiopia. BMC Int Health Hum Rights. BMC International Health and Human Rights; 2017;17(19):1-7.

36. Zhuang Shenyang, Xun Wu, Zunyou Poundstone, Katharine Yang, Changqing Zhong, Yaqin Jiang. HIV-related high-risk behaviors among chinese migrant construction laborers in nantong, jiangsu. PLoS One. 2012;7(3):1-6.

37. Pinyopornpanish, Kanokporn Thanamee, Sanhapan Jiraporncharoen, Wichuda Thaikla K. Sexual health , risky sexual behavior and condom use among adolescents young adults and older adults in Chiang Mai , Thailand: findings from a population based survey. BMC Res Notes [Internet]. BioMed Central; 2017;10(682):1-8. Available from: https://doi.org/10.1186/s13104-017-3055-1 
38. Green, K.M., Musci, R. J., Reboussin, B.A., lalongo, N.S. Developmental Patterns of Adolescent Marijuana and Alcohol Use and Their Joint Association with Sexual Risk Behavior and Outcomes in Young Adulthood. J Urban Heal. Journal of Urban Health; 2017;94:115-24.

39. Kiene SM, Barta WD, Tennen H, Armeli S. Alcohol, Helping Young Adults have Unprotected Sex with Casual Partners: Findings from a Daily Diary Study of Alcohol Use and Sexual Behavior. J Adolesc Heal. 2010;44(1):73-80.

40. Barker D., Christie R., Evan H., Norton A., Brown L.K. Sexting and Sexual Behavior in At-Risk Adolescents. Pediatrics. 2019;133:e276-82.

41. Kirby J, Sluijs W Van Der, Currie C. Attitudes towards condom use among young people. Univ ofEDINBURGH HBSC. 2010;18(b).

42. Ussher JM., Perz, J., Metusela, C., Hawkey, A. J., Morrow, M., Narchal, R., Estoesta, J. Negotiating Discourses of Shame, Secrecy, and Silence: Migrant and Refugee Women 's Experiences of Sexual Embodiment. Arch Sex Behav. Springer US; 2017;46(7):1901-21.

43. Anema A., Vogenthaler N., Frongillo, E. A., Kadiyala S., Weiser S. Food Insecurity and HIV / AIDS: Current Knowledge, Gaps, and. Curr HIV /AIDS Reports. 2009;6:224-31.

44. Bell J. Why embarrassment inhibits the acquisition and use of condoms: A qualitative approach to understanding risky sexual behaviour. J Adolesc [Internet]. Elsevier Ltd; 2009;32(2):379-91. Available from: http://dx.doi.org/10.1016/j.adolescence.2008.01.002

45. Kang HS, Moneyham L. Use of emergency contraceptive pills and condoms by college students: Int J Nurs Stud. 2008;45(5):775-83.

46. Elvis Enowbeyang Tarkang and Lilian Belole Pencille. Psychosocial predictors of consistent condom use among migrant road construction workers in the Southwest Region of Cameroonusing the Health Belief Model. Pan Afr Med J. 2018;8688:1-12.

\section{Figures}




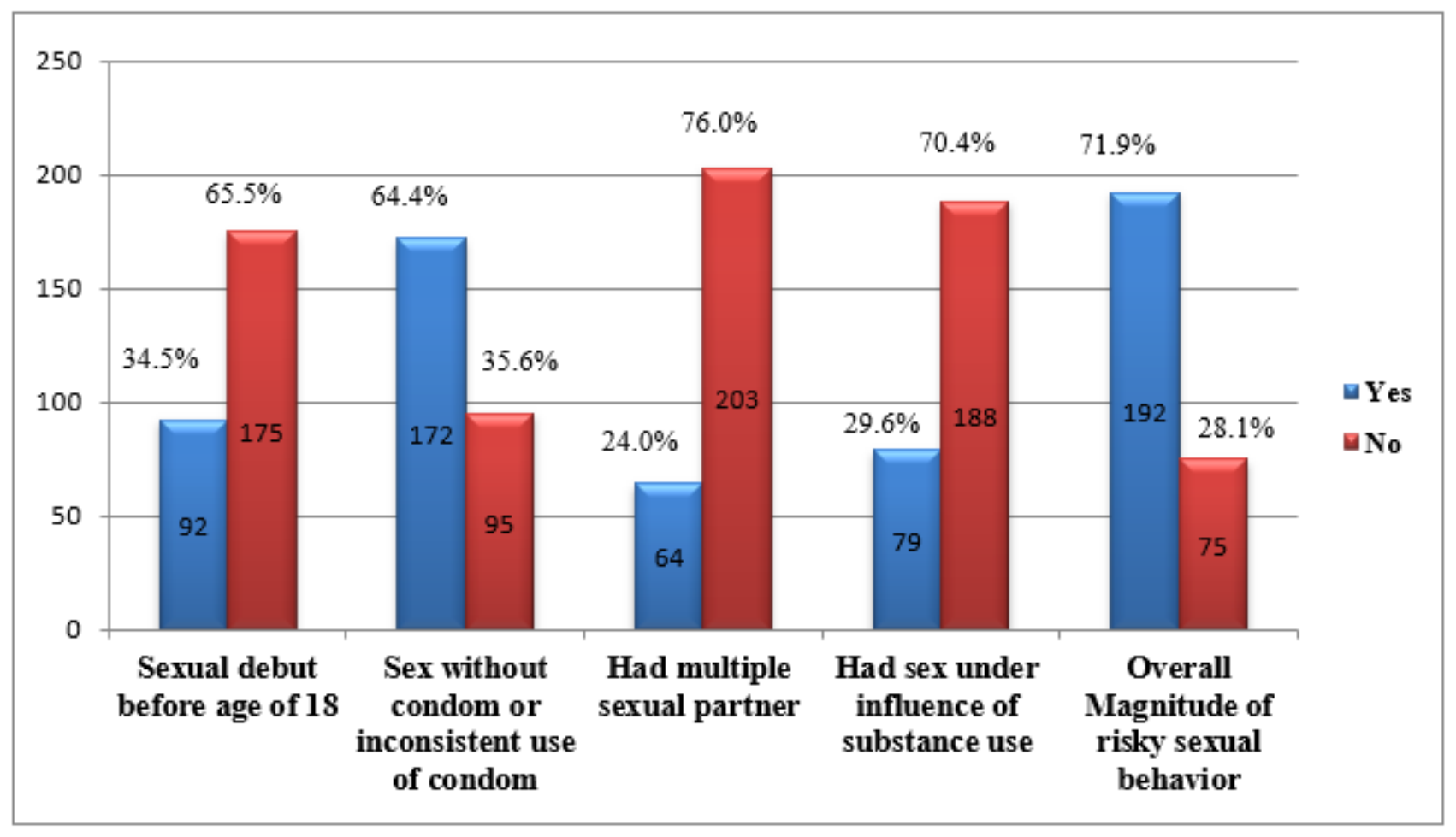

Figure 1

Magnitude of risky sexual behavior among sexually active unmarried young female internal migrants in Burayu town, Ethiopia. 